\title{
PINTURAS RUPESTRES EN EL NORTE SEMIÁRIDO DE CHILE: UNA PRIMERA APROXIMACIÓN FÍSICO-QUIMICA DESDE LA CUENCA DEL RÍO LIMARÍ (30 Lat. S)
}

\author{
ROCK ART PAINTINGS IN THE SEMIARID NORTH OF CHILE: A FIRST \\ PHYSICAL AND CHEMICAL APPROACH FROM THE LIMARI'S RIVER BASIN
}

Francisca Moya Andrés Troncoso $^{B}$, Marcela Sepúlvedac ${ }^{c}$ José Cárcamo $\&$ Sebastián Gutiérrez

En este trabajo entregamos una primera caracterización de las pinturas rupestres de la cuenca hidrográfica del río Limarí, que se asocian a grupos cazadores recolectores del Holoceno Tardío Inicial (ca. 2000 AC a 500 DC). A partir de análisis físicoquímicos moleculares, como microscopía y espectroscopía Raman, se identifican los pigmentos utilizados en la elaboración de estas representaciones pintadas, además de algunos componentes orgánicos. Los resultados obtenidos se discuten en relación con las dinámicas asociadas a la manufactura de estas representaciones por los cazadores recolectores que las ejecutaron. Finalmente, usando tal información y sobre todo los colores utilizados, se hipotetiza una secuencia cronológica de las pinturas rupestres.

Palabras clave: pinturas rupestres, espectrometría Raman, cazadores recolectores, producción, cronología, norte semiárido.

This paper offers a preliminary technological characterization of rock art paintings in the Limarí River Basin. Previous research has associated these paintings with Late Holocene hunter-gatherers (ca 2000 BCE to 500 CE). Molecular chemical-physical analyses of the paintings with microscopy and Raman Spectroscopy enabled the identification of the pigments used to produce this rock art as well as some organic components. The paper offers a discussion of those data in relation to local hunter-gatherer rock art production and proposes a chronological framework for the application of the different colors in the paintings.

Keywords: Semiarid North, rock paintings, Raman Spectrometry, hunter-gatherers, production, chronology.

\section{INTRODUCCIÓN}

De los tres niveles básicos de variabilidad del arte rupestre -visual, espacial y material-, este último es el que ha estado más relegado en la investigación arqueológica, no obstante la existencia de un conjunto de trabajos que lo han abordado entregando propuestas teóricas y metodológicas para definir atributos y variables a relevar (p. e. Álvarez \& Fiore 1995; Fiore 1996, 2007; Bednarik 1998, 2001; Whittaker et al. 2000; Álvarez et al. 2001; Keyser 2007; Valenzuela 2007, 2012; Méndez 2008; Sepúlveda \& Laval 2010; Krishna \& Kumar 2010-2011; Sepúlveda 2011; Sepúlveda et al. 2013a, 2013b; Vergara 2013; Vergara \& Troncoso 2015).

La dimensión tecnológica en las pinturas ha sido recurrentemente estudiada durante la última década gracias a la aplicación de una serie de técnicas físicoquímicas que posibilitaron la identificación y caracterización de las materias primas de las mezclas empleadas y de algunos procesos de conservación relacionados con la preservación de este tipo de manifestaciones (p. e. Prisloo 2007; Iriarte et al. 2009; Hernanz et al. 2010; Sepúlveda et al. 2012; Gheco et al. 2015). En

A Francisca Moya, proyecto Fondecyt 1150776, Santiago, Chile, email: franmoya.c@gmail.com

B Andrés Troncoso, Departamento de Antropología, Universidad de Chile, Santiago, Chile, email: atroncos@gmail.com

C Marcela Sepúlveda, Instituto de Alta Investigación, Laboratorio de Análisis e Investigaciones Arqueométricas, Universidad de Tarapacá, Arica, Chile, email: msepulveda@uta.cl; marcelaasre@gmail.com

D José Cárcamo, Laboratorio de Análisis e Investigaciones Arqueométricas, Universidad de Tarapacá, Arica, Chile, email: jcarcamo@uta.cl

E Sebastián Gutiérrez, Laboratorio de Análisis e Investigaciones Arqueométricas, Universidad de Tarapacá, Arica, Chile, email: sgutierrezv@uta.cl 


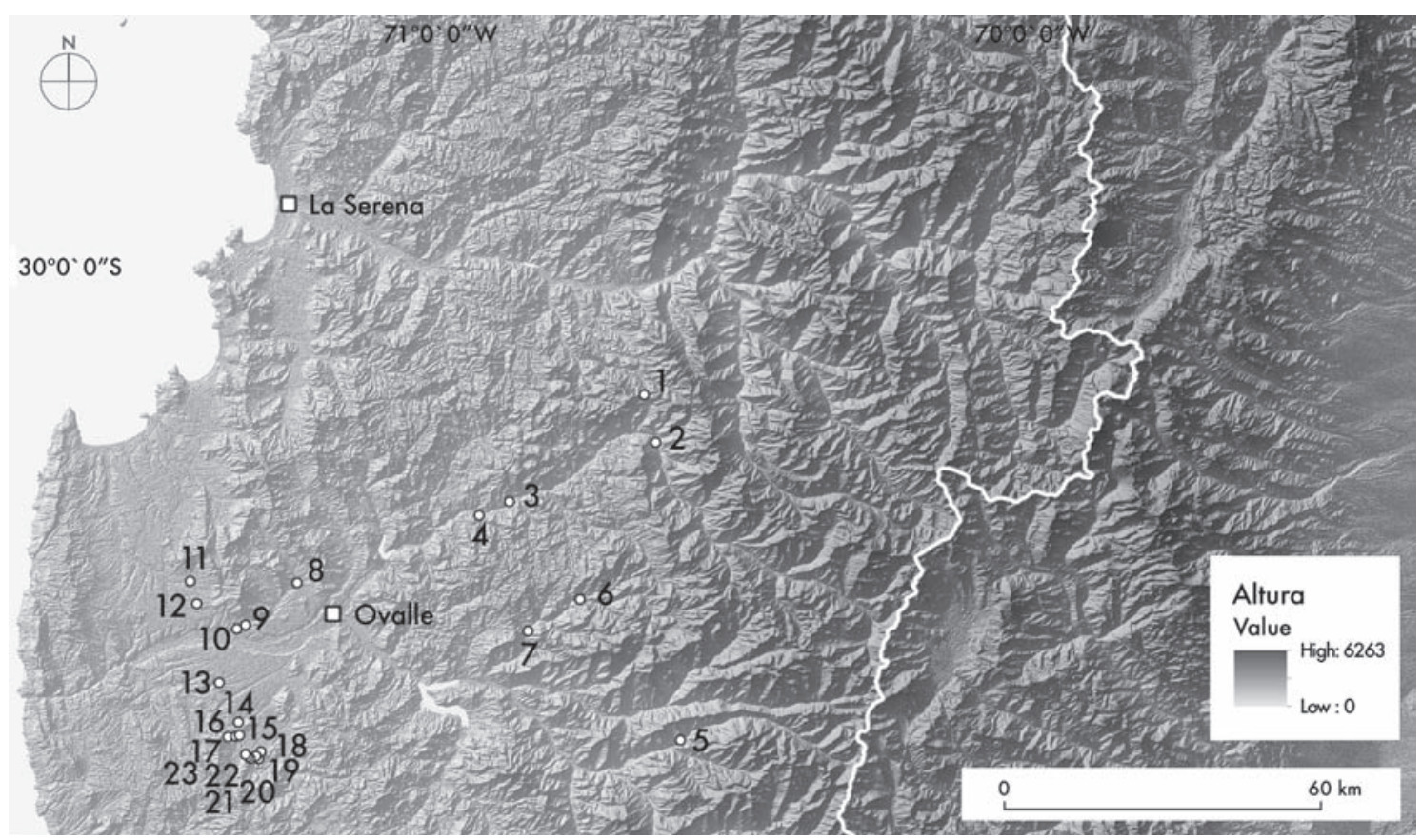

Figura 1. Mapa de la región con ubicación de los sitios estudiados. Figure 1. Map of the region showing the location of the sites studied.

general, estos trabajos y sus resultados han permitido abordar nuevas preguntas en relación con las cadenas operativas, el simbolismo de las materias primas, la historia de las pinturas y sus dinámicas de alteración (p. e. Ford et al. 1994; Edwards 2002; Tomasini et al. 2012a; Sepúlveda et al. 2013a y 2013b; Daher et al. 2013), así como la obtención de dataciones absolutas (p. e. Steelman \& Rowe 2012; Steelman et al. 2012; McDonald et al. 2014; Troncoso et al. 2015). En Chile, los estudios sobre pigmentos en pinturas rupestres se han concentrado en el norte grande, con algunos trabajos en Chile central y Patagonia (Mena 1983; Niemeyer \& León 2001; Sepúlveda 2009, 2010, 2011; Sepúlveda et al. 2012, 2013a, 2013b, 2014). Estos han mostrado una gran variabilidad en las composiciones de las pinturas de estas regiones, además de un uso diferencial de mezclas vinculado con la disponibilidad de materias primas y con el manejo de conocimientos específicos o decisiones tecnológicas particulares.

En el norte semiárido, las pinturas rupestres han sido objeto de pocos estudios arqueológicos, mayormente debido a su deteriorado estado de conservación (p. e. Ampuero 1966, 1985; Ampuero \& Rivera 1971a; Iribarren 1973a, 1973b; Cervellino 1985; Cervellino
\& Sills 2001). En el caso de la cuenca hidrográfica del río Limarí (Lat. S), la orientación de los trabajos ha sido descriptiva, sin que a la fecha se cuente con una caracterización físico-química que dé cuenta de su composición y que permita abordar otras dimensiones aparte de la visual. A la luz de lo anterior, en este estudio realizamos una primera aproximación físico-química molecular a las pinturas rupestres de la cuenca hidrográfica del río Limarí (fig. 1). Estas provienen de sitios asociados con cazadores-recolectores del Holoceno Tardío Inicial que habitaron la región entre los años 2.000 AC y 500 DC. Analíticamente, se observaron las muestras por microscopía para luego analizarlas molecularmente por espectroscopía Raman. A partir de estos resultados esbozamos una primera discusión relativa a las materias primas usadas para pintar las rocas y las dinámicas relacionadas con este proceso. Esta misma información, sumada a los atributos formales de las representaciones, es usada también para proponer una hipótesis sobre las posibles transformaciones que se dieron en el uso del color a lo largo del tiempo en que se manufacturaron las pinturas rupestres. 


\section{SOBRE LAS PINTURAS RUPESTRES EN LA CUENCA HIDROGRÁFICA DEL RÍO LIMARÍ}

Si bien el norte semiárido de Chile (en adelante NSA), y en específico la cuenca hidrográfica del río Limarí, tiene una larga historia de investigación en arte rupestre, lo cierto es que ella se ha enfocado mayormente en los petroglifos (p. e. Mostny \& Niemeyer 1983; Castillo 1985; Ballereau \& Niemeyer 1999; Niemeyer \& Ballereau 2004). Esto se debe tanto a su alta profusión en comparación a las pinturas, como a los problemas de registro que conlleva el deteriorado estado en que estas se encuentran. A pesar de lo anterior, diferentes autores han dado cuenta de la existencia de un conjunto no menor de sitios de pinturas rupestres para el NSA (Ampuero 1966 y 2010; Ampuero \& Rivera 1971a, 1971b; Iribarren 1973a, 1973b; Niemeyer \& Castillo 1996; Moya et al. 2014).

Las pinturas muestran un repertorio iconográfico constituido casi exclusivamente por diseños no figurativos con un claro predominio del color rojo, aunque también se describe el uso del verde y amarillo. Si bien su aspecto temporal no ha sido ampliamente discutido, en oposición a lo que ocurre con los petroglifos, la propuesta cronológica de Ampuero y Rivera (1964), emanada de sus investigaciones en valle El Encanto, ha sido la más aceptada. En particular, proponen que las pinturas se relacionarían con el complejo cultural El Molle del Período Alfarero Temprano (ca. 0-900DC). Esta asociación fue posteriormente reafirmada por Iribarren (1973a), aunque dejó abierta la posibilidad de una filiación con cazadores Arcaicos. Recientemente, Ampuero (2010), también ha sugerido la posible presencia de pinturas en el Arcaico Tardío, pero con mayor recurrencia durante el Alfarero Temprano.

En los últimos años, hemos desarrollado un conjunto de trabajos en diversos espacios de la cuenca hidrográfica del río Limarí orientados al estudio del arte rupestre, con prospecciones sistemáticas que abarcaron un área cercana a los $150 \mathrm{~km}^{2}$ (Troncoso et al. 2016). El amplio espacio comprendido por nuestro survey regional, sumado a los antecedentes de sitios conocidos previamente y al uso de nuevas tecnologías de registro, como son las fotografías digitales y su procesamiento computacional por medio de paquetes informáticos, nos permitieron identificar y registrar nuevos sitios con pinturas rupestres, así como realizar una serie de análisis formales y comparativos de los motivos, previamente dificultados debido a su mal estado de conservación.
A la fecha, hemos identificado un total de 23 sitios con pinturas rupestres que comprenden 43 rocas pintadas (tabla 1) (fig. 1). Gracias a las observaciones y el registro en terreno, sumados al procesamiento computacional de las fotografías digitales por medio del software Adobe Photoshop y el paquete informático D-Stretch-Image J (Harman 2008 [2005]; Acevedo \& Franco 2012), reconocimos un total de 225 figuras pintadas. De estas, 69 corresponden simplemente a manchones no identificables, producto de su deterioro, mientras que 156 se consignaron como motivos claramente distinguibles.

Para caracterizar y evaluar la variabilidad de las pinturas hemos desarrollado una aproximación basada en definir sus unidades básicas, reglas sintácticas y atributos de color (ver Troncoso 2005). Luego, a partir de estos dos primeros aspectos hemos propuesto una tipología de motivos para la región (Moya et al. 2014; Moya 2015). Las pinturas son mayormente monocromas $(92,9 \%)$, con un escaso registro de motivos bícromos $(5,8 \%)$ y trícromos (1,3\%) (fig. 2). Independientemente del tipo de pintura, el color más utilizado es el rojo $(87,8 \%)$, aunque se reconoce también el amarillo (16\%), el negro $(3,8 \%)$ y el verde (1,3\%). Las pinturas bícromas combinan los colores rojo y amarillo o negro, mientras que las trícromas combinan rojo, amarillo y verde. $\mathrm{Si}$ bien el alto predominio del color rojo puede relacionarse con su mayor capacidad de conservación (Casanova 2011), pensamos que también refleja su mayor uso. A modo de ejemplo, San Pedro Viejo de Pichasca es un sitio con muy buenas condiciones de preservación de las representaciones, y este presenta la mayor variedad y cantidad de pinturas en toda el área (tabla 1), pero priman notablemente los motivos rojos por sobre los de otros colores (Moya et al. 2014).

En los motivos predominan los no figurativos (96,2\%), y se reconocen solo 6 de tipo figurativo: dos positivos de mano en San Pedro Viejo de Pichasca (fig. 2b) y cuatro representaciones circulares o cuadrangulares que recuerdan a las cabezas tiaras y máscaras de tiempos posteriores (Mostny \& Niemeyer 1983) (fig. 2a). Si bien en un trabajo previo (Troncoso et al. 2008) sugerimos la presencia de un antropomorfo en valle El Encanto, un nuevo procesamiento digital de tales imágenes, pero esta vez con D-Stretch, muestra que este corresponde en realidad a un motivo lineal no figurativo.

Los motivos no figurativos son elaborados básicamente con líneas, círculos y cuadriláteros. La mayoría son de geometría lineal (74\%), de las que destacan las 
Tabla 1. Sitios de arte rupestre estudiados en la cuenca hidrográfica del río Limarí. Table 1. Rock art sites studied at the hidrographic basin of Limari river.

\begin{tabular}{|c|c|c|c|c|c|}
\hline Sector & Sitio & $\begin{array}{l}\text { Coordenadas } \\
\text { UTM (WGS 84) }\end{array}$ & $\begin{array}{l}\text { Número } \\
\text { de Bloques }\end{array}$ & $\begin{array}{l}\text { Número de } \\
\text { motivos }\end{array}$ & $\begin{array}{l}\text { Colores } \\
\text { Usados }\end{array}$ \\
\hline \multirow[t]{16}{*}{ Tierras Bajas } & Alero La Pintura & $\begin{array}{r}277989 \\
6586866 \\
\end{array}$ & 1 & 1 & Rojo \\
\hline & Altos de La Rinconada & $\begin{array}{r}279792 \\
6588068 \\
\end{array}$ & 1 & 7 & Rojo \\
\hline & Cárcavas & $\begin{array}{r}274380 \\
6590654 \\
\end{array}$ & 1 & 1 & Rojo \\
\hline & Covacha Pintada & $\begin{array}{r}275503 \\
6590696 \\
\end{array}$ & 2 & 10 & Rojo, negro \\
\hline & El Tranque & $\begin{array}{r}276189 \\
6591021 \\
\end{array}$ & 1 & 1 & Rojo \\
\hline & La Placa 1 & $\begin{array}{r}276776 \\
6611739 \\
\end{array}$ & 3 & 8 & Rojo \\
\hline & La Placa 5 & $\begin{array}{r}275319 \\
6611040 \\
\end{array}$ & 1 & 1 & Rojo, negro \\
\hline & Melina & $\begin{array}{r}276098 \\
6593436 \\
\end{array}$ & 2 & 1 & Rojo \\
\hline & Pinturas de Rumay & $\begin{array}{r}267567 \\
6619815 \\
\end{array}$ & 3 & 16 & Rojo \\
\hline & Valle del sol 11 & $\begin{array}{r}285002 \\
6619847 \\
\end{array}$ & 1 & 2 & Rojo \\
\hline & Valle El Encanto & $\begin{array}{r}272684 \\
6600761 \\
\end{array}$ & 11 & 39 & Rojo \\
\hline & El Molino & $\begin{array}{r}279361 \\
6586800 \\
\end{array}$ & 2 & 0 & Rojo \\
\hline & La Piedra Mula & $\begin{array}{r}277784 \\
6587329 \\
\end{array}$ & 1 & 0 & Rojo \\
\hline & Rocas de Francisca & $\begin{array}{r}279029 \\
6587126 \\
\end{array}$ & 3 & 0 & Rojo \\
\hline & Piedras del fondo & $\begin{array}{r}277269 \\
6587435 \\
\end{array}$ & 1 & 0 & Rojo \\
\hline & Tamaya 6 & $\begin{array}{r}268760 \\
6615481 \\
\end{array}$ & 1 & 0 & Rojo \\
\hline \multirow[t]{7}{*}{ Tierras Altas } & $\begin{array}{c}\text { San Pedro } \\
\text { Viejo de Pichasca }\end{array}$ & $\begin{array}{r}319227 \\
6635727 \\
\end{array}$ & 1 & 56 & $\begin{array}{c}\text { Rojo, amarillo } \\
\text { y verde }\end{array}$ \\
\hline & Los Maitenes 1 & $\begin{array}{r}347782 \\
6591293 \\
\end{array}$ & 1 & 7 & Rojo, negro \\
\hline & Ponio B & $\begin{array}{r}331165 \\
6617471 \\
\end{array}$ & 1 & 4 & Rojo, amarillo \\
\hline & Las Tinajas & $\begin{array}{r}314446 \\
6633032 \\
\end{array}$ & 1 & 1 & Rojo \\
\hline & Tres Cruces & $\begin{array}{r}341043 \\
6656076 \\
\end{array}$ & 2 & 0 & Rojo \\
\hline & Maray & $\begin{array}{r}342966 \\
6647157 \\
\end{array}$ & 1 & 1 & Rojo \\
\hline & Ponio 5 & $\begin{array}{r}322629 \\
6611390\end{array}$ & 1 & 0 & Rojo \\
\hline
\end{tabular}



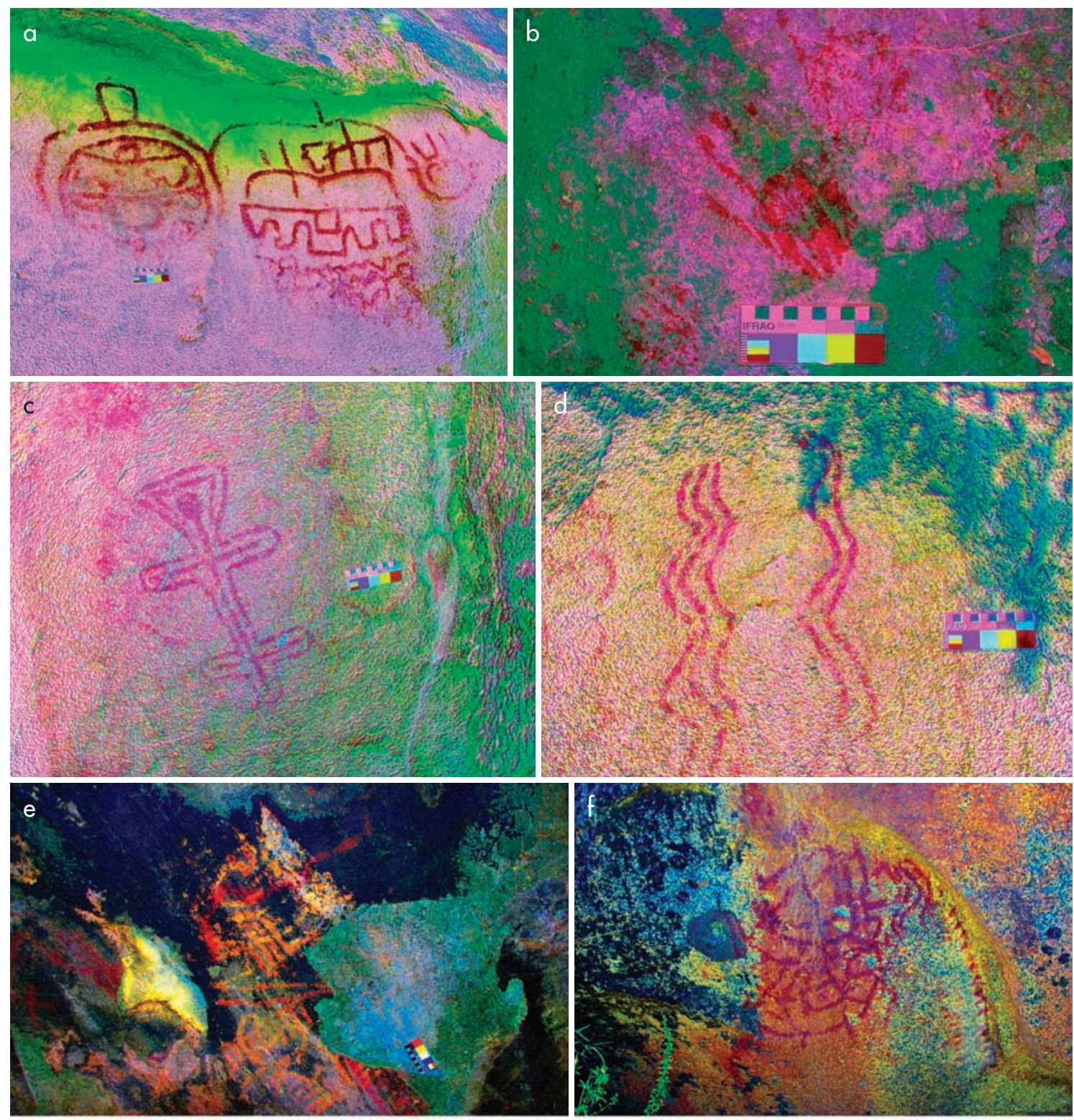

Figura 2. Ejemplos de motivos reconocidos en las pinturas rupestres de Limarí. Motivos figurativos: a) Los Maitenes, b) San Pedro Viejo de Pichasca. Motivos no figurativos: c) valle El Encanto, d) valle El Encanto; e) San Pedro Viejo de Pichasca, f) valle El Encanto. Figure 2. Sample of motifs identified in the rock paintings of Limarí. Figurative motifs: $\boldsymbol{a})$ Los Maitenes; $\boldsymbol{b}$ ) San Pedro Viejo de Pichasca. Non-figurative motifs: c) El Encanto valley; d) El Encanto valley; e) San Pedro Viejo de Pichasca; f) El Encanto valley.

representaciones conformadas por líneas simples dispuestas en diferentes sentidos. En otros casos se trata de múltiples líneas combinadas en diseños más complejos. En cantidad, siguen los diseños compuestos por círculos u óvalos (17\%) y cuadrados/rectángulos (5\%), la mayoría de los cuales presentan decoración interna. A estos se suman unos pocos motivos elaborados a partir de puntos (2\%), rombos (1\%) y trapecios (1\%) (Moya 2015). La simetría se emplea como recurso visual en cerca de la mitad de los motivos estudiados (46,2\%), sobre todo la traslación (31,4\%) y la reflexión especular (14,7\%) (fig. 2). La presencia de este set de principios sobre distintas 


\section{Tipos de diseños no figurativos}

LÍNEAS

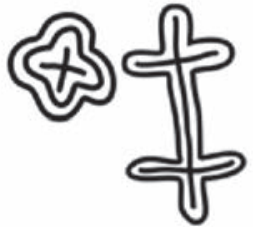

1 Cruces inscritas

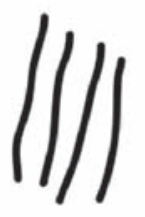

2 Líneas rectas en traslación

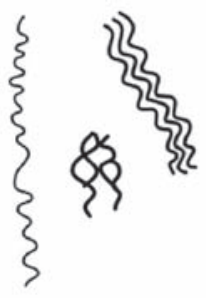

3 Meandros

\section{CÍRCULOS}

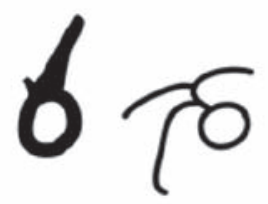

4 Círculo con apéndices lieales

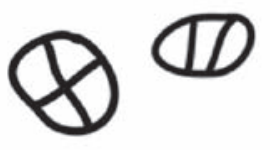

5 Círculo con decoración interna
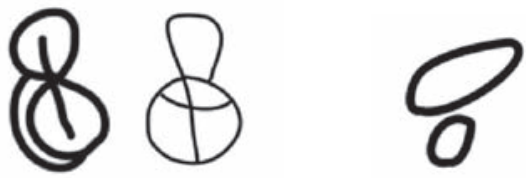
6 Círculos yuxtapuestos

7 Círculo simple

\section{CUADRADOS, ROMBOS Y TRAPECIOS}

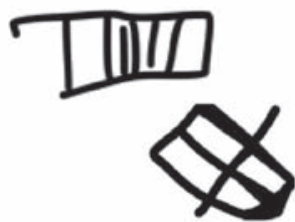

8 Cuadrado con decoración interna

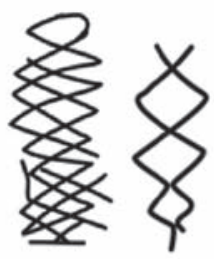

9 Rombos yuxtapuestos

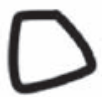

10 Trapecio simple

Figura 3. Tipología de motivos en pinturas rupestres según Moya (2015). Figure 3. Typology of the motifs in rock paintings according to Moya (2015).

representaciones permite la construcción de una gran diversidad de motivos rupestres en coherencia con la naturaleza politética de estos conjuntos (Clarke 1984; Davis 1993; Troncoso 2005). No obstante lo anterior, Moya (2015) ha propuesto una tipología de 10 diseños para la región que permiten dar cuenta de esta variabilidad (fig. 3).

Las superposiciones entre pinturas son escasas: se reconocen solamente cuatro, distribuidas en dos sitios, San Pedro Viejo de Pichasca y Pinturas de Rumay. En 
este último, se observan dos casos de diseños lineales rojos superpuestos entre sí, mientras que en San Pedro Viejo de Pichasca ambas superposiciones presentan rojo sobre amarillo. En uno de ellos caso se trata de un diseño lineal sobre otro con la misma geometría, mientras que en el segundo, de un diseño lineal sobre uno de geometría cuadrangular.

Espacialmente, las pinturas se distribuyen a lo largo de toda la cuenca hidrográfica del río Limarí, pero con una clara concentración en las tierras bajas (Moya 2015; Troncoso et al. 2016) (fig. 1). Las pinturas suelen disponerse al interior de los campamentos residenciales de cazadores recolectores del Holoceno Tardío Inicial, sean estos sitios a cielo abierto, predominantes en tierras bajas o reparos rocosos, de mayor número en el espacio cordillerano (Moya 2015; Troncoso et al. 2016). Excavaciones realizadas en sitios como Melina, valle El Encanto, Tamaya, Alero Cachaco o Alero Cabrito indican que en asociación con las pinturas se encuentran densos depósitos de cultura material producto de actividades residenciales de cazadores recolectores del Holoceno Tardío. Estos contextos muestran la presencia de fogones, conjuntos líticos variados con diversidad de materias primas y cadenas operativas incompletas caracterizados por instrumentos variados, que incluyen puntas de proyectil, cuchillos, raspadores y derivados de núcleos. Los registros zooarqueológicos, a su vez, se conforman sobre todo por restos de camélidos, preferentemente astillas óseas con diferentes grados de carbonización (Troncoso et al. 2016). En estos sitios es recurrente encontrar también restos de pigmentos, la mayoría de color rojo.

En términos cronológicos, y como fuera adelantado en cierta medida por Iribarren (1973a) y Ampuero y Rivera (1964, ver también Ampuero 2010), este conjunto de pinturas rupestres se asocia con los cazadores recolectores del Holoceno Tardío, específicamente con comunidades del Arcaico Tardío (2000 AC a 0) y los primeros momentos del Alfarero Temprano (0-500 DC) (Troncoso et al. 2015). Aunque una cronología vinculada con dos períodos diferentes podría cuestionarse, nuestros estudios en la zona, que han considerado evaluaciones de conjuntos de cultura material, patrones de asentamiento y dataciones absolutas de contextos arqueológicos, demuestran que la aparición de la alfarería no habría generado un cambio rotundo en las dinámicas de las poblaciones cazadoras recolectoras del Holoceno Tardío (Troncoso et al. 2016), situación que también es reconocida en otros espacios del NSA (p. e. Pavlovic 2004; Méndez et al. 2009). Por el contrario, se observa una continuidad entre las ocupaciones del Arcaico Tardío y las primeras ocupaciones del Alfarero Temprano, generándose un quiebre recién hacia el 500 DC, vinculado con la aparición de los grandes cementerios con ruedos de piedra (p. e. La Turquía), un cambio en los patrones de asentamiento y una popularización de la alfarería entre estos grupos. Este cambio se expresaría en el arte rupestre con la desaparición de las pinturas y la aparición de los grabados de surco profundo (Troncoso et al. 2016). La continuidad en la producción de pinturas entre estos dos periodos, por lo tanto, sería el resultado de una serie de otras continuidades observables en el registro arqueológico. A manera de antecedentes de lo anterior, cabe mencionar que Punta Teatinos, uno de los principales sitios asociados con la construcción de la secuencia arqueológica de la región, muestra este mismo proceso de continuidad en relación con prácticas funerarias (p. e. Quevedo 1998).

Las razones que fundamentan la atribución cronológica de las pinturas al Arcaico Tardío y Alfarero Temprano son: (1) no obstante la esperable variabilidad de los conjuntos pintados, estos se ajustan a un repertorio básico de formas, diseños, patrones de simetría y emplazamiento que les entrega unidad (Moya 2015); (2) la similitud de los patrones de simetría y motivos pintados con aquellos reconocidos en otros soportes materiales, como son, por ejemplo, los instrumentos de hueso de Punta Teatinos; (3) la presencia recurrente de pigmentos en los contextos estratigráficos habitacionales asociados con este momento, situación que no se observa ni antes ni después; (4) la identificación de una clara relación entre el emplazamiento de bloques con pinturas rupestres y sitios residenciales de este lapso temporal, varios de los cuales presentan dataciones absolutas directas (tabla 2). Por último, recientemente hemos realizado dos dataciones radiocarbónicas directas de pinturas de color negro en los sitios de Covacha Pintada y La Placa 5, las que entregaron fechas coherentes con dichos períodos (1623-1431 cal. AC y 80-240 DC cal DC) (Troncoso et al. 2015). Si bien las dataciones absolutas deben ser siempre evaluadas con cautela, especialmente debido al problema del "Old Wood" (Schiffer 1986), sus resultados son coherentes con las otras líneas de evidencia descritas anteriormente, las cuales avalan la asociación de las pinturas con este momento. Destaca, en este sentido, la contemporaneidad observada entre 
Tabla 2. Dataciones absolutas de ocupaciones del Holoceno Tardío Inicial asociadas a contextos con pinturas rupestres o restos de pigmentos en estratigrafía (fechas calibradas con curva ShCal 13 en Oxcal 4.2). Table 2. Absolute datations of Initial Late Holocene occupations asociated with rock paintings or pigment remains in stratigraphy (dates calibrated with ShCal 13 curve in Oxcal 4.2).

\begin{tabular}{|c|c|c|c|c|c|c|c|}
\hline Sitio & Proveniencia & Material & Código & $14 \mathrm{C}$ años BP & $\begin{array}{l}2 \sigma \mathrm{Cal} \\
\mathrm{AC}-\mathrm{DC}\end{array}$ & $\begin{array}{c}13 \mathrm{C} / 12 \mathrm{C} \\
\text { ratio } \%\end{array}$ & Fuente \\
\hline \multirow[t]{4}{*}{$\begin{array}{l}\text { Valle } \\
\text { El Encanto }\end{array}$} & PL3: $10-20 \mathrm{~cm}$ & $\begin{array}{l}\text { Hueso de Lama } \\
\text { guanicoe }\end{array}$ & $\begin{array}{c}\text { UGAMS } \\
9353\end{array}$ & $3680 \pm 25$ & $\begin{array}{c}2127 \mathrm{a} \\
1892 \mathrm{AC}\end{array}$ & $\begin{array}{c}\text { No } \\
\text { disponible }\end{array}$ & $\begin{array}{c}\text { FONDECYT } \\
1110125\end{array}$ \\
\hline & PL1: $90 \mathrm{~cm}$ & Carbón & $\begin{array}{c}\text { AA } \\
95189 \\
\end{array}$ & $2579 \pm 36$ & $\begin{array}{c}799 \mathrm{a} \\
514 \mathrm{AC}\end{array}$ & $-22,6$ & $\begin{array}{c}\text { FONDECYT } \\
1110125 \\
\end{array}$ \\
\hline & PL3: $70 \mathrm{~cm}$ & Carbón & $\begin{array}{c}\text { UGAMS } \\
05013\end{array}$ & $2000 \pm 25$ & $\begin{array}{c}36 \mathrm{AC} \\
\text { a } 129 \mathrm{DC} \\
\end{array}$ & -22.8 & $\begin{array}{c}\text { FONDECYT } \\
1110125 \\
\end{array}$ \\
\hline & $\mathrm{MP} 1: 35 \mathrm{~cm}$ & Carbón & $\begin{array}{c}\text { UGAMS } \\
05014\end{array}$ & $1890 \pm 25$ & $\begin{array}{c}86 \mathrm{a} \\
248 \mathrm{DC}\end{array}$ & -23.7 & $\begin{array}{c}\text { FONDECYT } \\
1110125\end{array}$ \\
\hline \multirow[t]{2}{*}{ Tamaya 1} & $\mathrm{U} 1: 40 \mathrm{~cm}$ & $\begin{array}{c}\text { Hueso de } \\
\text { Lama guanicoe }\end{array}$ & $\begin{array}{c}\text { UGAMS } \\
11772 \\
\end{array}$ & $3290 \pm 25$ & $\begin{array}{c}1608 \mathrm{a} \\
1432 \mathrm{AC}\end{array}$ & $-19,7$ & $\begin{array}{c}\text { FONDECYT } \\
1110125 \\
\end{array}$ \\
\hline & U1: Feature 1 & $\begin{array}{c}\text { Hueso de } \\
\text { Lama guanicoe }\end{array}$ & $\begin{array}{c}\text { UGAMS } \\
9352\end{array}$ & $3200 \pm 25$ & $\begin{array}{c}1497 \mathrm{a} \\
1320 \mathrm{AC}\end{array}$ & -17 & $\begin{array}{c}\text { FONDECYT } \\
1110125\end{array}$ \\
\hline Melina 1 & $\mathrm{U} 2: 35 \mathrm{~cm}$ & $\begin{array}{c}\text { Hueso de } \\
\text { Lama guanicoe }\end{array}$ & $\begin{array}{c}\text { UGAMS } \\
11771\end{array}$ & $1680 \pm 25$ & $\begin{array}{c}325 \mathrm{a} \\
537 \mathrm{DC}\end{array}$ & $-22,7$ & $\begin{array}{c}\text { FONDECYT } \\
1110125\end{array}$ \\
\hline \multirow[t]{2}{*}{$\begin{array}{l}\text { San Pedro } \\
\text { Viejo de Pichasca }\end{array}$} & E1D1: $30 \mathrm{~cm}$ & Carbón & I5957 & $2375 \pm 95$ & $\begin{array}{c}767 \mathrm{a} \\
202 \mathrm{AC} \\
\end{array}$ & $\begin{array}{c}\text { No } \\
\text { disponible }\end{array}$ & $\begin{array}{c}\text { Ampuero \& } \\
\text { Rivera 1971b }\end{array}$ \\
\hline & $\begin{array}{c}\text { Mandíbula } \\
\text { Mamífero con } \\
\text { pigmento rojo }\end{array}$ & Hueso & $\begin{array}{c}\text { UGAMS } \\
22817\end{array}$ & $2150 \pm 25$ & $\begin{array}{l}337 \mathrm{a} \\
58 \mathrm{AC}\end{array}$ & $-7,5$ & $\begin{array}{c}\text { FONDECYT } \\
1150776\end{array}$ \\
\hline \multirow[t]{3}{*}{ Alero El Puerto } & $\begin{array}{c}\text { Unidad } 1, \\
\text { Capa B, } 70 \mathrm{~cm}\end{array}$ & $\begin{array}{c}\text { Hueso } \\
\text { camélido }\end{array}$ & $\begin{array}{c}\text { UGAMS } \\
13129\end{array}$ & $3630 \pm 25$ & $\begin{array}{c}2026 \mathrm{a} \\
1780 \mathrm{AC}\end{array}$ & $-23,7$ & $\begin{array}{c}\text { FONDECYT } \\
1110125\end{array}$ \\
\hline & $\begin{array}{c}\text { Unidad 2, } \\
\text { Capa C, } 59 \mathrm{~cm}\end{array}$ & $\begin{array}{c}\text { Hueso } \\
\text { camélido }\end{array}$ & $\begin{array}{c}\text { UGAMS } \\
22813\end{array}$ & $4060 \pm 25$ & $\begin{array}{c}2620 \mathrm{a} \\
2469 \mathrm{AC}\end{array}$ & $-9,9$ & $\begin{array}{c}\text { FONDECYT } \\
1150776\end{array}$ \\
\hline & $\begin{array}{c}\text { Unidad 2, } \\
\text { Capa B, } 24 \mathrm{~cm}\end{array}$ & $\begin{array}{c}\text { Hueso } \\
\text { camélido }\end{array}$ & $\begin{array}{c}\text { UGAMS } \\
22814\end{array}$ & $2940 \pm 25$ & $\begin{array}{l}1210 \mathrm{a} \\
996 \mathrm{AC}\end{array}$ & $-12,7$ & $\begin{array}{c}\text { FONDECYT } \\
1150776\end{array}$ \\
\hline \multirow[t]{3}{*}{ Punta Teatinos } & Tumba 146 & $\begin{array}{c}\text { Hueso } \\
\text { humano }\end{array}$ & $\begin{array}{l}\text { Beta } \\
4514\end{array}$ & $3320 \pm 70$ & $\begin{array}{c}1756 \mathrm{a} \\
1438 \mathrm{AC}\end{array}$ & $\begin{array}{c}\text { No } \\
\text { disponible }\end{array}$ & $\begin{array}{l}\text { Schiapaccase \& } \\
\text { Niemeyer } 1986\end{array}$ \\
\hline & Tumba 40 & $\begin{array}{c}\text { Hueso } \\
\text { humano }\end{array}$ & $\begin{array}{l}\text { Beta } \\
4515\end{array}$ & $3000 \pm 70$ & $\begin{array}{c}1414 \mathrm{a} \\
1040 \mathrm{AC}\end{array}$ & $\begin{array}{c}\text { No } \\
\text { disponible }\end{array}$ & $\begin{array}{l}\text { Schiapaccase \& } \\
\text { Niemeyer } 1986\end{array}$ \\
\hline & Tumba 178 & $\begin{array}{l}\text { Hueso } \\
\text { humano }\end{array}$ & $\begin{array}{l}\text { Beta } \\
4516\end{array}$ & $1920 \pm 60$ & $\begin{array}{c}43 \mathrm{AC} \\
\text { a } 232 \mathrm{DC}\end{array}$ & $\begin{array}{c}\text { No } \\
\text { disponible }\end{array}$ & $\begin{array}{c}\text { Schiapaccase \& } \\
\text { Niemeyer 1986; } \\
\text { Quevedo } 1998\end{array}$ \\
\hline
\end{tabular}


algunas dataciones absolutas provenientes de depósitos estratigráficos y aquellas de las pinturas rupestres (Troncoso et al. 2015).

Un aspecto que puede llamar la atención es la presencia de cruces inscritas que asignamos a este momento, aun cuando para el caso de los grabados las hemos asociado con el Período Tardío o Inkaico (Troncoso 2005; González 2011; Troncoso et al. 2016). Esta situación no debería extrañar. Por un lado, es un motivo no muy complejo que bien puede darse de manera independiente en distintos tiempos y espacios. Por otro, sus características difieren entre pinturas y grabados, lo que sugiere una distancia temporal. En el primer caso, las cruces son de tamaños más grandes que las de los grabados y suelen presentarse unidas con otras cruces, lo que no sucede en los petroglifos. A su vez, las cruces pintadas no suelen compartir espacios con los grabados, y se emplazan en lugares y relieves distintos, evidencia de que sus paisajes de producción divergerían. Finalmente, sus composiciones en los paneles y en los sitios difieren también, pues mientras las cruces inscritas en los petroglifos suelen formar parte de abigarrados paneles con multiplicidad de motivos y en sitios con una gran cantidad de bloques intervenidos (que llegan a sobrepasar los 100 bloques), en el caso de las pinturas, estas forman parte de paneles visualmente "livianos", es decir, que no contienen una alta cantidad de motivos, situación que se reitera a nivel del sitio, donde la cantidad de bloques intervenidos suele ser baja (sin sobrepasar la docena de rocas marcadas). Todo esto indica, por tanto, que por sobre una aparente similitud de un motivo se dan sintaxis diferentes en su representación (cruces unidas versus no unidas), en sus articulaciones al interior de los paneles y de los sitios, así como en su emplazamiento, todo lo cual hace suponer que ellas remiten a momentos y contextos históricos diferentes.

Las características y la temporalidad de las pinturas rupestres de esta región se diferencian de aquellas reconocidas en el extremo septentrional del norte semiárido. Tales diferencias se refieren a sus aspectos visuales y temporales, pues en las pinturas de la zona de Copiapó, junto con los diseños no figurativos se reconoce una importante presencia de representaciones antropomorfas, algunas de las cuales han sido asociadas con la noción del sacrificador (p. e. Cervellino 1992). Lo anterior ha llevado a sugerir su relación con el Período Medio (Cervellino 1992; Cervellino \& Sills 2001; San Francisco \& Ballester 2010), no obstante la posibilidad de que puedan existir pinturas de tiempos previos, así como ulteriores. Esta variabilidad entre el extremo norte y el centro del nsa no debe extrañar, por cuanto las trayectorias temporales y sociales de ambos espacios son completamente distintas y responden a diferentes dinámicas y procesos históricos particulares (Troncoso \& Pavlovic 2013).

\section{MATERIAL Y MÉTODO}

Para este trabajo se analizaron 23 muestras de pinturas rupestres con el fin de caracterizar su composición físico-química. En la tabla 3 se resume el conjunto de muestras tomadas y las características específicas de los motivos, así como sus sitios de procedencia.

Las muestras de pintura se tomaron siguiendo los protocolos respectivos (Sepúlveda \& Laval 2010; Steelman \& Rowe 2012). Se extrajeron porciones milimétricas de pintura buscando alterar mínimamente los motivos. Cada muestra fue obtenida utilizando un bisturí cuyo cuchillo estéril fue cambiado tras cada extracción. Las partículas fueron depositadas al interior de tubos plásticos eppendorf, los que fueron sellados en terreno para evitar posibles alteraciones o pérdidas durante su transporte a laboratorio.

Antes de su caracterización, cada muestra fue observada mediante microscopio trinocular con sistema de epifluorescencia (marca Optika, modelo B-600TiFl), con aumentos variables entre 400x y 40x y luz blanca, a partir de lo cual se realizó una descripción general de las muestras.

Posteriormente, los espectros Raman, realizados en el Laboratorio de Análisis e Investigaciones Arqueométricas de la Universidad de Tarapacá (Arica, Chile) fueron registrados en un equipo Renishaw InViaReflex, equipado con fuentes de excitación de 532, 633 y $785 \mathrm{~nm}$, un microscopio Leica y una cámara CCD enfriada eléctricamente. Las medidas micro-Raman fueron calibradas usando una placa de silicio y un objetivo de 50x. La resolución fue ajustada a $4 \mathrm{~cm}$ - 1 y entre 1 y 20 barridos con tiempos entre 10 y $30 \mathrm{~s}$. El poder del láser 785 fue ajustado entre $10 \mathrm{y}$ $100 \mathrm{~mW}$. Los espectros fueron registrados en la región comprendida entre 1800 y $100 \mathrm{~cm}-1$. Los espectros reproducibles fueron escaneados directamente sobre las muestras depositadas sobre una placa de cuarzo, para así atenuar o apagar su fluorescencia natural. Se 
Tabla 3. Caracterización de la muestra de estudio y resultados obtenidos. Table 3. Characterization of the study sample and obtained results.

\begin{tabular}{|c|c|c|c|}
\hline Color & Sitio & Motivo & Resultado \\
\hline \multirow[t]{15}{*}{ Rojo } & Los Maitenes 1 & Cabeza & Hematita \\
\hline & Melina & Motivo lineal & Hematita \\
\hline & Alero La Pintura & Motivo lineal & Hematita \\
\hline & Valle El Encanto & Motivo lineal & Hematita \\
\hline & \multirow[t]{2}{*}{ Covacha Pintada } & Círculo con decoración interna & Hematita \\
\hline & & Rectángulo con decoración interna & Hematita \\
\hline & Pinturas de Rumay & Motivo lineal & Hematita \\
\hline & La Placa 5 & Círculo con decoración externa & $\begin{array}{c}\text { Hematita, material } \\
\text { proteíco }\end{array}$ \\
\hline & \multirow[t]{3}{*}{ Ponio B } & Motivo lineal & Hematita, oxalatos \\
\hline & & Motivo lineal & Hematita, oxalatos \\
\hline & & Motivo lineal & Hematita, oxalatos \\
\hline & \multirow[t]{4}{*}{ San Pedro Viejo de Pichasca } & Motivo lineal & Hematita \\
\hline & & Motivo lineal & Hematita \\
\hline & & Motivo lineal & Hematita \\
\hline & & Motivo lineal & Hematita \\
\hline \multirow[t]{4}{*}{ Negro } & \multirow[t]{2}{*}{ Los Maitenes 1} & Motivo lineal & Carbón amorfo \\
\hline & & Círculo con apéndices lineales & Carbón amorfo \\
\hline & La Placa 5 & Círculo con decoración externa & Carbón amorfo \\
\hline & Covacha Pintada & Rectángulo con decoración interna & Carbón amorfo \\
\hline Verde & San Pedro Viejo de Pichasca & Motivo lineal & $\begin{array}{l}\text { Sulfato de cobre, } \\
\text { oxalatos }\end{array}$ \\
\hline \multirow[t]{3}{*}{ Amarillo } & Ponio B & Motivo lineal & Goethita, oxalatos \\
\hline & \multirow[t]{2}{*}{ San Pedro Viejo de Pichasca } & Motivo lineal & Goethita \\
\hline & & Motivo lineal & Goethita \\
\hline
\end{tabular}


utilizaron los programas Wire 3.4 y GRAMS/AI 8 para analizar la información espectral. Todas las muestras fueron analizadas directamente sin preparación previa, de modo de poder someterlas a análisis posteriores. Los espectros Raman se registraron recorriendo diferentes zonas de cada muestra, de manera tal de obtener un espectro único y reproducible. Los espectros obtenidos fueron comparados con la base de datos RRUFF (Downs 2006), así como con lo registrado en otros casos de estudio descritos en la bibliografía pertinente.

\section{RESULTADOS}

A partir de los análisis realizados observamos que las muestras caracterizadas microscópicamente como rojo corresponden a hematita, oxido férrico de fórmula molecular $\mathrm{Fe}_{2} \mathrm{O}_{3}$. Esta identificación molecular es sustentada por la presencia de las bandas en torno a 226, 500 y $613 \mathrm{~cm}^{-1}$ (fig. 4).

Los análisis a las muestras de amarillo dieron cuenta de que los perfiles espectrales pueden ser clasificados como goethita. Esta identificación molecular es confirmada sobre la base de la presencia de las bandas en torno a $251,302,391$ y $556 \mathrm{~cm}^{-1}$ (fig. 5), resultado comparable con los descritos en RRUFF (Downs 2006).

Para el caso de las muestras negras, el análisis espectral identifica claramente el uso de carbón amorfo como base de la composición pictórica, lo que es evidente por la presencia de las bandas cercanas a 1335 y $1590 \mathrm{~cm}^{-1}$, correspondiente a las bandas D y G de carbón amorfo (fig. 6) (Lahlil et al. 2012; Tomasini et al. 2012b). Un análisis más acabado del perfil espectral nos permite inferir que el carbón amorfo identificado no tiene como fuente de origen restos óseos, debido a la ausencia de la banda característica cercana a $970 \mathrm{~cm}^{-1}$ (Lahlil et al. 2012; Tomasini et al. 2012b; Gomes et al. 2013). Además, en ningún caso fue posible identificar otros componentes presentes en esta capa pictórica, como por ejemplo, aglutinantes o cargas.

Por último, el espectro Raman realizado a la muestra verde permitió asignar un conjunto de bandas que pudieron ser asociadas con sulfato de cobre, probablemente antlerita o brochantita (fig. 7) (Martens et al. 2003). El uso de este tipo de mineral en pintura ya había sido identificado en el norte grande (Sepúlveda et al. 2014), pero esta es la primera vez que es caracterizado en el norte semiárido. El espectro obtenido

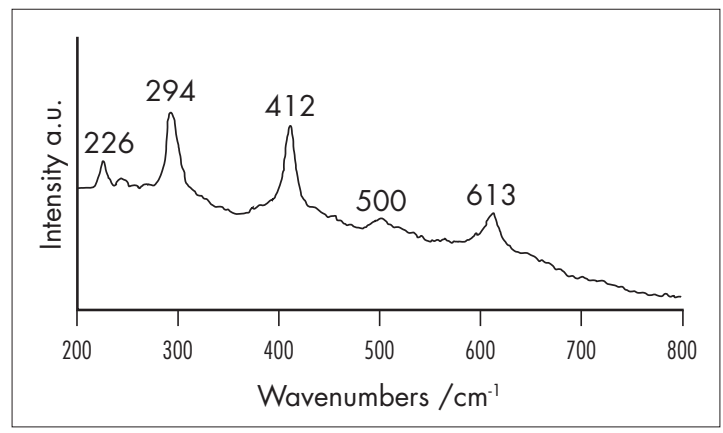

Figura 4. Espectros Raman de hematita (color rojo) identificado en sitio El Ponio B. Figure 4. Raman spectres of hematite (color red) identified at site El Ponio B.

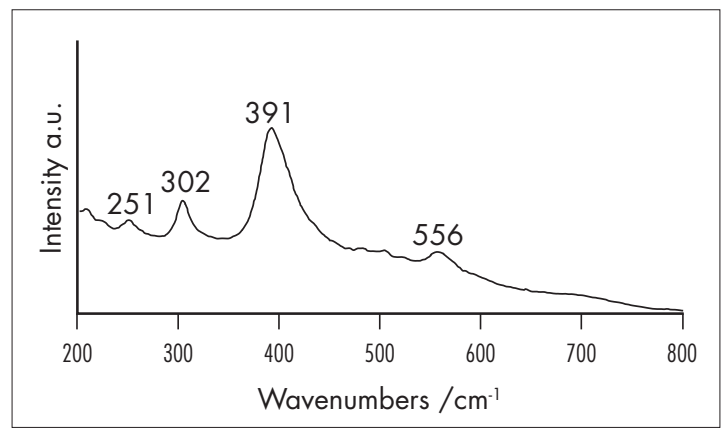

Figura 5. Espectros Raman de goethita (color amarillo) identificado en sitio El Ponio B. Figure 5. Raman spectres of goethite (color yellow) identified at site El Ponio B.

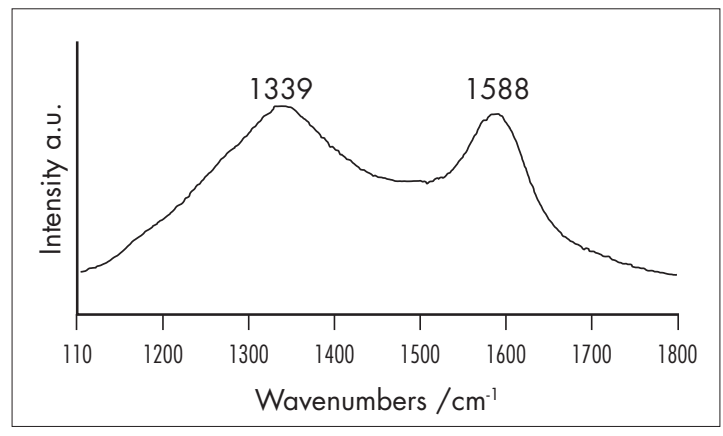

Figura 6. Espectros Raman de carbón (color negro) identificado en sitio los Maitenes. Figure 6. Raman spectres of carbon (color black) identified at site El Ponio B.

es poco claro, lo que puede deberse a la combinación de distintos minerales de cobre y posibles cargas en la elaboración de la pintura.

Un aspecto complementario a la identificación de los materiales colorantes de las pinturas refiere a la pre- 
sencia de material orgánico como posible aglutinante. Es así como destacan en algunas muestras un conjunto de bandas con intensidad variable, ubicadas en el rango comprendido entre 1000 y $1800 \mathrm{~cm}^{-1}$ (fig. 8). A partir de trabajos previos en el análisis vibracional Raman sobre compuestos orgánicos y sistemas biológicos (Cárcamo et al. 2012a, 2012b), así como de datos publicados (Frost et al. 2008; Vandenabeele et al. 2000), podemos proponer la presencia de oxalatos y material proteico en la mezcla pictórica. Como se muestra en la línea superior, la existencia de oxalatos puede ser inferida por la observación de las bandas ubicadas a 1465 y $1497 \mathrm{~cm}^{-1}$, mientras que en la línea inferior podemos atribuir las bandas a1665, 1526 y $1292 \mathrm{~cm}^{-1}$ a los modos de vibración amida I, amida II y amida III, respectivamente, correspondientes a la estructura secundaria de proteínas. Debido a la presencia de diferentes tipos de compuestos en un mismo espectro, no fue posible proponer alguna proteína específica en la mezcla pictórica (tabla 3).

El reconocimiento de los diferentes compuestos en las muestras analizadas, y especialmente de oxalatos en algunas de ellas, abre la posibilidad de llevar a cabo nuevas dataciones absolutas de pinturas rupestres que permitan continuar afinando su cronología (Steelman et al. 2002; Watchman et al. 2005; Steelman \& Rowe 2012).

\section{DISCUSIÓN}

Los resultados obtenidos nos permiten efectuar un primer acercamiento a la composición físico-química de las pinturas rupestres de la cuenca hidrográfica del río Limarí. Consideramos que las muestras estudiadas, por su número, distribución y por abarcar los diferentes colores reconocidos en la zona, dan cuenta en buena medida de las materias colorantes utilizadas en estos contextos.

Como hemos indicado, el color rojo es el más abundante en las pinturas de la región, a la vez que el más muestreado en nuestro estudio. Los análisis evidencian el uso de hematita, un mineral de empleo frecuente en el arte rupestre mundial (Hradil et al. 2003; Rapp 2009). Aunque no tenemos estudios de procedencia de fuentes, lo cierto es que los óxidos de hierro son uno de los minerales más comunes en el planeta y son recurrentes en el área, pues se reconocen yacimientos de hierro en la Cordillera de la Costa (Ulriksen 1990) y es esperable encontrar óxidos de hierro como depósitos residuales

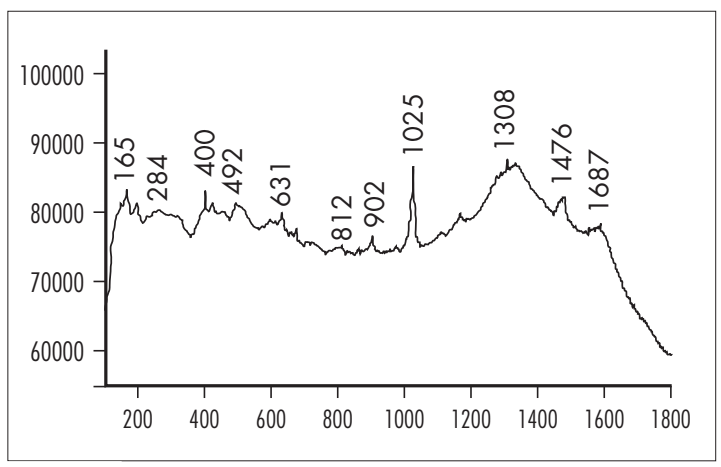

Figura 7. Espectro Raman de sulfato de cobre (color verde) identificado en San Pedro Viejo de Pichasca. Figure 7. Raman spectre of copper sulphate (color green) identified at site El Ponio B.

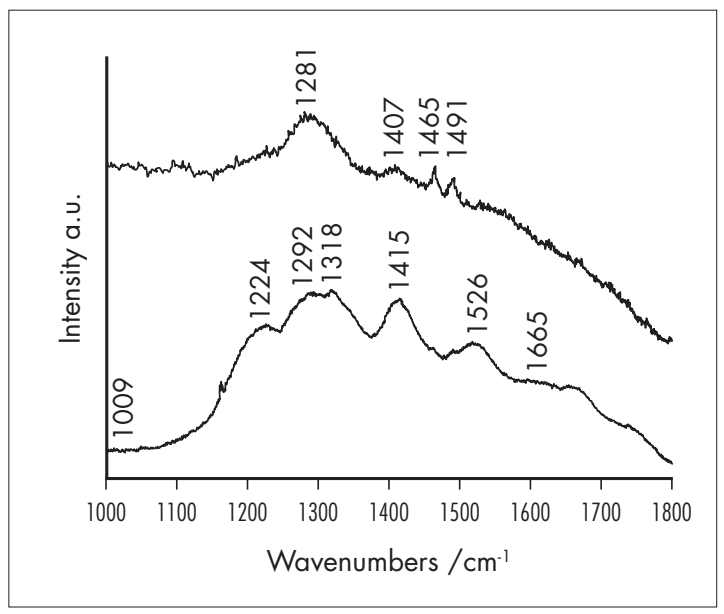

Figura 8. Espectro Raman de muestras que presentan componentes orgánicos (oxalatos y material proteico). Figure 8. Raman spectre of samples presenting organic components oxalates and proteic material) identified at site El Ponio B.

asociados con otros yacimientos minerales y formaciones rocosas. Aunque se reconocen pigmentos rojos en la zona desde el Holoceno Temprano, vinculados con la presencia de instrumentos de molienda (p. e. Llagostera et al. 1998), estos parecen popularizarse en relación con las prácticas funerarias de los cazadores recolectores desde el inicio del Holoceno Tardío (p. e. sitios Guanaqueros, Museo del Desierto, Punta Teatinos; Iribarren 1956; Schiappacase \& Niemeyer 1964; Kuzmanic \& Castillo 1986). Lamentablemente, en estos últimos casos no se cuenta con análisis químicos que aseguren que la materia colorante corresponda a hematita.

El color amarillo, de uso menos frecuente, corresponde a goethita, otro mineral de gran presencia en la 
corteza terrestre (Rapp 2009), así como en la región. Sin embargo, contrasta con esta amplia disponibilidad el hecho de que solo se encuentren pinturas amarillas en tierras altas y no en tierras bajas de la zona, a pesar de que su disponibilidad debiese ser similar o superior a la de la hematita. No hemos hallado referencias a otras materias colorantes amarillas en la región, excepto unos pequeños aglomerados recuperados en las excavaciones del sitio Alero Roca Fértil. Estos se asocian con una ocupación de cazadores recolectores del Holoceno Tardío Inicial, aunque a la fecha estas tampoco han sido analizadas.

La producción del color negro se relacionaría también con un proceso de fácil accesibilidad a los recursos, por cuanto corresponde a carbón amorfo, el que puede ser obtenido en los mismos sitios residenciales donde se inscriben las pinturas rupestres. Es interesante que en otros contextos de cazadores recolectores, específicamente en el norte grande de Chile, el negro de las pinturas corresponda siempre -hasta ahora- a minerales de manganeso (Sepúlveda et al. 2013b), que ha sido también identificado en el recubrimiento de las momias Chinchorro (Sepúlveda et al. 2013b y 2015). En nuestro caso, Alaniz (1973) identifica minerales de manganeso en pigmentos negros recuperados del sitio La Herradura. Estos resultados indicarían que se empleó dos materias primas para producir el color negro. Tales diferencias, sin embargo, no se relacionarían con la disponibilidad de estos recursos minerales, por cuanto a partir del mapa metalogénico de la zona se reconocen fuentes de óxidos de manganeso en la porción norte de la cuenca hidrográfica del río Limarí, en el sector de Samo Alto (Urliksen 1990). Esta selección reflejaría entonces decisiones tecnológicas que, por sobre el uso de un mismo color, diferencian las materias primas sobre las cuales se manufactura tal pigmento.

Finalmente, la única muestra estudiada de color verde corresponde a un sulfato de cobre (brochantita o antlerita); en primera instancia, esto podría advertir sobre un proceso más complejo de manufactura que los anteriores. Su menor representación en el registro arqueológico podría ser indicador de lo mismo, pues esta es la única pintura de dicho color reconocida en la región hasta el momento. El uso de sulfato de cobre como pigmento parece popularizarse en la zona recién en época Diaguita, y se le reconoce también en la manufactura del color negro en la cerámica polícroma de estas comunidades (Seguel et al. 2005).
A la fecha, no hemos identificado específicamente las fuentes de aprovisionamiento, ni sitios asociados con la obtención de las distintas materias primas mencionadas, por lo que desconocemos cómo se desplegó el sistema de aprovisionamiento. Sin embargo, los estudios regionales que hemos desarrollado sugieren que estas comunidades dispusieron de un sistema de movilidad de tipo residencial, sin que se haya identificado sitios de orientación logística (Troncoso et al. 2016). Aunque esto pueda ser producto de un sesgo de la investigación, lo cierto es que en principio es hipotetizable que al menos algunas materias primas se adquirieran a partir de desplazamientos cortos desde esos mismos espacios. Esto se basa en el hecho de que tanto la hematita como la goethita se presentan como depósitos residuales de múltiples formaciones rocosas y minerales, por lo que estarían ampliamente disponibles a nivel regional. El carbón se pudo efectuar en los mismos sitios habitacionales por medio de actividades de combustión. El verde presenta una situación intermedia, pues si bien es menos recurrente que los óxidos de hierro en la corteza terrestre, el mapa metalogénico de la zona evidencia múltiples fuentes de minerales de cobre, las que presentan una mayor concentración en el sector inferior de Limarí (Urliksen 1990).

La etapa final de la producción de las pinturas rupestres habría acontecido en los mismos sitios habitacionales. Esta hipótesis responde al hallazgo recurrente de restos de pigmentos, especialmente rojo, en los contextos estratigráficos de los sitios residenciales. A manera de ejemplo, en el sitio Tamaya 1 se recuperó un pequeño mortero con su superficie cubierta de pigmento rojo en una capa datada en 1608-1432 AC (Troncoso et al. 2015) (tabla 2). A su vez, como parte del patrón de estructuración de los sitios residenciales de estas comunidades, las piedras tacitas son parte del furniture del espacio habitacional, al entregar el soporte material para su manufactura. Aunque no hemos realizado estudios dirigidos específicamente a muestrear pigmentos en piedras tacitas, lo cierto es que se reconocen algunos restos rojizos en su superficie, lo que sugiere que ellas podrían relacionarse con la cadena productiva del procesamiento de los minerales.

La identificación de componentes proteicos como un posible aglutinante de los pigmentos es obtenible de los mismos restos zooarqueológicos reconocidos en estos sitios, los que si bien son cazados fuera del asentamiento, son incorporados a manera de carcasas 
a los espacios residenciales (Troncoso et al. 2016). Como hemos discutido en otro trabajo (Troncoso \& Armstrong en prensa), estos antecedentes sugieren que la práctica de pintado del arte rupestre no está segregada en términos de las audiencias que las conforman. No solo las pinturas pueden ser observadas por todos los miembros de la unidad residencial al emplazarse en los campamentos, sino que también, al menos los momentos finales de preparación de los pigmentos pudieron ser parte de una experiencia comunal, pues se realizaban en los mismos espacios donde se desarrollaban una serie de otras actividades. La información con que contamos no permite identificar si la práctica misma de pintado fue propia de diferentes sujetos o, por el contrario, exclusiva de solo algunos. De esta manera, las pinturas rupestres se integraron dentro de una práctica comunitaria y colectiva que no implicó una mayor segregación de las actividades y espacios cotidianos tanto para su manufactura como para su observación; en cambio privilegiaron en su despliegue el actuar del conjunto del grupo social. Tanto a nivel local como extra-regional nos parece relevante la presencia de cobre como materia prima para la manufactura de pinturas rupestres en estos contextos tempranos. Esto puede dar alguna indicación para establecer una cronología relativa al interior de las mismas pinturas.

Los datos con que contamos muestran que las pinturas se manufacturaron a lo largo de cerca de 2.000 años (Troncoso et al. 2015, 2016), por lo que no es de extrañar que existieran cambios durante este lapso temporal. Si bien el trabajo de Moya (2015) no permite reconocer una cronología interna a partir de los atributos formales de estas representaciones, pensamos que usando la información aquí presentada es posible plantear una diferenciación temporal.

El uso del color rojo se extendería a lo largo de toda la secuencia temporal de manufactura de pinturas rupestres. Su asociación con momentos más tempranos viene dada tanto por un fechado absoluto del sitio Covacha Pintada, donde se dató el pigmento negro de un diseño bícromo negro-rojo (Troncoso et al. 2016), como por el uso de pigmentos rojo en contextos funerarios desde finales del Holoceno Medio e inicios del Holoceno Tardío (p. e. Schiappacasse \& Niemeyer 1964; Alaniz 1973; Quevedo 1998). Su ubicación en los momentos finales se reitera por otro fechado absoluto del sitio La Placa 5, donde nuevamente se dató un diseño bícromo negro-rojo (Troncoso et al. 2016), así como por el reco- nocimiento de pinturas rojas con representaciones de cabezas similares a las que se identifican posteriormente en los grabados. Cabe señalar que estas cabezas incluyeron en su representación color negro, pero las dataciones absolutas obtenidas arrojaron fechas subactuales, lo que hace suponer una contaminación de la muestra.

El color negro también estaría distribuido a lo largo de toda la secuencia de pinturas, como lo indican los dos fechados absolutos directos obtenidos de motivos de este color. El color amarillo podría presentar una expresión más reducida temporalmente. Esto se debe a que en los pocos casos en que se identifica, está en relación de superposición con otras pinturas, en un caso de color rojo y en otra de color verde. Esta última superposición también indicaría que el verde se habría realizado en momentos posteriores a las demás pinturas.

Finalmente, consideramos que el uso del color verde sería una expresión tardía dentro de la cronología de las pinturas rupestres. Ello no solo por su escaso registro, sino también porque los casos conocidos a la fecha para la región sugieren la ausencia del uso de minerales de cobre en momentos anteriores a la era cristiana. Usando la cronología tradicional del área, la tecnología asociada con el cobre, tanto en forma de cuentas como en placas metálicas, se reconoce solo desde el Alfarero Temprano en adelante (Iribarren 1958, 1970; Ampuero 1971), por lo cual podemos sostener que este color se comienza a usar en los momentos finales de las pinturas (al menos después del año 0 ).

Proponemos, por tanto, una secuencia en la que rojos y negros se extienden a lo largo de los 2.000 años de manufactura de las pinturas. Amarillos y verdes, por el contrario, podrían asociarse a segmentos particulares de tal secuencia, en la cual el amarillo es anterior al verde. Aunque estos datos son preliminares, efectivamente permiten delinear una secuencia cronológica a poner a prueba con nuevos datos y dataciones absolutas.

\section{CONCLUSIONES}

En este trabajo hemos realizado una primera aproximación a las pinturas rupestres de la cuenca hidrográfica del río Limarí considerando su composición físico-química. A la vez, combinando tal información con otros indicadores arqueológicos hemos propuesto una secuencia temporal de uso de colores. La necesidad de contar con pigmentos para la elaboración de las pinturas, así como la distribu- 
ción de este tipo de recursos, muestra de qué manera su manufactura implicó la espacialización de su producción, para la cual fueron necesarias una serie de prácticas. La aplicación de cada color habría implicado una serie de procedimientos espaciales particulares, respecto de los cuales son relevantes dos aspectos: las decisiones tecnológicas relacionadas con ciertas producciones pigmentarias y la secuencia cronológica relativa establecida a partir de la producción de determinados colores.

Específica y primeramente, las diferencias en las materias primas usadas para manufacturar el color negro en contextos rupestres y funerarios sugeriría una toma de decisiones tecnológicas diferentes para la preparación de esta tonalidad. Aunque aún exploratoria, esta separación podría dar cuenta de la relevancia que tienen, junto con el color, las materias primas y el proceso de manufactura en la vida social de los objetos, recordando la idea de "tecnología de encantamiento" propuesta por Gell (1998).

En segundo lugar, subyaciendo a nuestra hipótesis de secuencia temporal de uso de los colores, encontraríamos que durante los 2.000 años de manufactura de pinturas rupestres las prácticas de producción se transformarían, ya que la explotación del amarillo y del verde no sería recurrente en el tiempo. Estos cambios se asociarían con dinámicas espaciales (adquisición de nuevas materias primas), prácticas (procesamiento de estas materias) y simbólicas (valores). En esa línea, es necesario explorar a futuro si estos cambios en la dimensión de los colores son acompañados con modificaciones en los motivos, pues el actual corpus de representaciones no permite discutir en profundidad tal aspecto.

A pesar de las divergencias respecto de los usos y la adquisición de las distintas materias primas para la producción de los distintos colores, ellas se integran dentro de similares ámbitos fenoménicos y espaciales, al replicar un patrón espacial de emplazamiento que evidencia una integración de esta materialidad con un conjunto de otras prácticas, audiencias y experiencias.

Si bien nuestros resultados son aún preliminares, permiten continuar profundizando en el conocimiento y entendimiento de las pinturas rupestres del norte semiárido, un tipo de registro hasta ahora insuficientemente abordado en comparación con otros conjuntos materiales. En particular, resulta necesario profundizar en sus caracterizaciones físico-químicas para reconocer de mejor manera sus atributos tecnológicos, pero también avanzar en el refinamiento de la cronología para la obtención de nuevas dataciones absolutas directas o indirectas (p. e. oxalatos sobre las pinturas) que nos permitan contrastar nuestra hipótesis temporal y evaluar las transformaciones que sufrieron estas manifestaciones a lo largo de sus casi 2.000 años de producción. El frágil y deteriorado estado de conservación en que se encuentra este registro hace que el desarrollo de nuevas investigaciones sea una tarea urgente en el contexto de recuperación y valorización de esta materialidad, antes de su total desaparición.

RECONOCIMIENTOS A CONICYT que financió este trabajo por medio de los proyectos FONDECYT 1150776 y 1110125 . Al Museo Nacional de Historia Natural, Museo Arqueológico de La Serena, Museo del Limarí, Convenio de Desempeño UTA-MINEDUC e Iniciativa Bicentenario Juan Gómez Millas por su apoyo a la realización de esta investigación. A Mara Basile por la figura 3. A todos los compañeros y compañeras del proyecto Limarí sin cuyo trabajo este artículo no sería posible, así como a los evaluadores anónimos que con sus comentarios permitieron mejorar nuestro trabajo.

\section{REFERENCIAS}

Acevedo, A. \& N. Franco, 2012. Aplicación de DStretch-ImageJ a imágenes digitales del arte rupestre de Patagonia (Argentina). Comechingonia Virtual 6 (2): 152-175.

Alaniz, J., 1973. Excavaciones arqueológicas en un conchal precerámico La Herradura, Provincia de Coquimbo, Chile. Boletín del Museo Arqueológico de La Serena 15: 189-213.

Álvarez, M. \& D. Fiore, 1995. Recreando imágenes: diseño de experimentación acerca de las técnicas y los artefactos para realizar grabados rupestres. Cuadernos del Instituto Nacional de Antropología y Pensamiento Latino Americano 16: 215-240.

Álvarez, M.; D. Fiore, E. Favret \& R. Castillo, 2001. The use of lithic artefacts for making rock art petroglyphs: observation and analysis of use-wear trace through optical microscopy and sem. Journal of Archaeological Science 28: 457-464.

Ampuero, G., 1966. Pictografías y petroglifos de la Provincia de Coquimbo: El Panul, Lagunillas y El Chacay. Notas del Museo Arqueológico de La Serena 9: 1-13.

Ampuero, G., 1971. Nuevos resultados de la arqueología del norte chico. En Actas del vi Congreso Nacional de Arqueología Chilena, pp. 311-338. Santiago: Universidad de Chile-Sociedad Chilena de Arqueología.

Ampuero, G., 2010. Prehistoria de la región de Coquimbo. Santiago: Andros.

Ampuero, G., 1985. El arte rupestre en el norte chico, análisis y proposiciones metodológicas. En Estudios en arte rupestre, C. Aldunate. J. Berenguer \& V. Castro, Eds., pp. 413-416. Santiago: Museo Chileno de Arte Precolombino.

Ampuero, G. \& M. Rivera, 1964. Excavaciones en la quebrada El Encanto, Departamento de Ovalle (informe preliminar). En Actas del III Congreso Internacional de Arqueología Chilena, Arqueología de Chile central y áreas vecinas, pp. 207-218. Viña del Mar: Sociedad Chilena de Arqueología. 
Ampuero, G. \& M. Rivera, 1971a. Las manifestaciones rupestres y arqueológicas del valle del Encanto. Boletín del Museo Arqueológico de La Serena 14: 71-103.

Ampuero, G. \& M. Rivera, 1971b. Secuencia arqueológico del alero rocoso de San Pedro Viejo de Pichasca. Boletín del Museo Arqueológico de La Serena 14: 45-69.

BALlereau, D. \& H. NiEMEYeR, 1999. Los sitios rupestres del valle del río Hurtado superior (norte chico, Chile). Chungara 31 (2): 229-292.

BEDNARIK, R., 1998. The technology of petroglyphs. Rock Art Research 15 (1): 23-35.

BEDNARIK, R., 2001. Rock art science: The scientific study of palaeoart. Belgium: Brepols.

Cárcamo, J.; A. Aliaga, E. Clavijo, M. Brañes \& M. CamposVAllette, 2012a. Raman study of the shockwave effect on collagens. Spectrochim Acta 86: 360-365.

Cárcamo, J.; A. Aliaga, E. Clavijo, M. Brañes \& M. CamposVALLETTE, 2012b. Raman and surface-enhanced Raman scattering in the study of human rotator cuff tissues after shock wave treatment. Journal of Raman Spectroscopy 43: 248-254.

Casanova, P., 2011. Primeros reconocimientos sobre el estado de conservación de pinturas rupestres en el sector del Alto Loa, Región de Antofagasta, Chile. Boletín del Museo Chileno de Arte Precolombino 16 (1): 47-66.

Castillo, G., 1985. Revisión del Arte Rupestre Molle. En Estudios en arte rupestre, C. Aldunate, J. Berenguer \& V. Castro, Eds., pp. 173-194. Santiago: Museo Chileno de Arte Precolombino.

Cervellino, M., 1985. Evaluación del arte rupestre en la III Región de Atacama. En Estudios en arte rupestre, C. Aldunate, J. Berenguer \& V. Castro, Eds., pp. 355-371. Santiago: Museo Chileno de Arte Precolombino

Cervellino, M., 1992. La imagen del sacrificador en el arte rupestre de la región atacameña. Boletín del Museo Regional de Atacama 4: 161-174.

Cervellino, M. \& N. Sills, 2001. El arte rupestre de los sitios Finca de Chañaral y Quebrada de Las Pinturas, Región de Atacama. En Segundas Jornadas de Arte y Arqueología, J. Berenguer, L. Cornejo, F. Gallardo \& C. Sinclaire, Eds., pp. 134-151. Santiago: Museo Chileno de Arte Precolombino.

Clarke, D., 1984. Arqueología analítica. Barcelona: Bellaterra.

DAVIS, W., 1993. Style and history in art history. En The uses of style in archaeology, M. Conkey \& C. Hastorf, Eds., pp. 18-31. Cambridge: Cambridge University Press.

Daher, C.; L. Bellot-Gurlet, A. Le Hô, C. Paris \& M. Reggert, 2013. Advanced discriminating criteria for natural organic substances of cultural heritage interest: Spectral decomposition and multivariate analyses of ft-Raman and ft-ir signatures. Talanta 115: 540-547.

Downs, R., 2006. The RRUfF Project: an integrated study of the chemistry, crystallography, Raman and infrared spectroscopy of minerals. En Program and Abstracts of the 19th General Meeting of the International Mineralogical Association. Kobe, Japón.

EDWARDS, H., 2002. Raman microscopy in art and archaeology, ilumination of historical mysteries in rock art and frescoes. Spectroscopy 17 (2): 16-24.

FIORE, D., 1996. El arte rupestre como producto complejo de procesos ideológicos y económicos: una propuesta de análisis. Espacio, Tiempo y Forma. Serie I, Prehistoria y Arqueología 9: 239-259.

Fiore, D., 2007. The economic side of rock art: concepts on the production of visual images. Rock Art Research 24 (2): 149-160.

Ford, B.; I. MACLEOD \& P. HAYDOCK, 1994. Rock art pigments from Kimberley Region of western Australia: Identification of the minerals and conversion mechanisms. Studies in Conservation 39 (1): 57-69.

Frost, R.; L. Ashley \& M. Wayde, 2008. Synthesis and Raman spectroscopic characterisation of the oxalate mineral wheatleyite $\mathrm{Na} 2 \mathrm{Cu} 2+(\mathrm{C} 2 \mathrm{O} 4) 2.2 \mathrm{H} 2 \mathrm{O}$. Journal of Raman Spectroscopy 39: 901-908.

GeLL, A., 1998. Art and agency: An anthropological perspective. Oxford: Clarendon Press.

Gheco, L.; R. Álvarez, A. Poliszuk \& M. Quesada, 2015. Caracterización química de pinturas rupestres prehispánicas del sitio arqueológico de Oyola mediante SEM-EDS, DRX, FT-IR y FRX. En Arqueometría argentina: metodologías científicas aplicadas al estudio de los bienes culturales, A. Pifferetti \& I. Dosztal, Eds., pp. 271-284. Buenos Aires: Aspha.

Gomes, H.; R. Pierluigi, P. Holakooei, T. Solomon \& C. Vaccaro, 2013. Identification of pigments used in rock art paintings in Gode Roriso-Ethiopia using Micro-Raman Spectroscopy. Journal of Archaeological Science 40: 4073-4082.

GonZÁLEZ, P., 2008. Universo representacional del arte rupestre del sitio Los Mellizos (Provincia del Choapa): convenciones visuales y relaciones culturales. Boletín del Museo Chileno de Arte Precolombino 16 (2): 49-59.

Hernanz, A.; J. Ruiz-López, J. M. Gavira-Vallejo, S. Martin \& E. GaVrilenko, 2010. Raman microscopy of prehistoric rock paintings from the Hoz de Vicente, Minglanilla, Cuenca, Spain. Journal of Raman Spectroscopy 41: 1394-1399.

Hradil, D.; T. Grygar, J. Hradilová \& P. BezdičKa, 2003. Clay and iron oxide pigments in the history of painting. Applied Clay Science 22: 223-236.

HARMAN, J., 2008 [2005]. Using decorrelation stretch to enhance rock art images. <http://dstretch.com/AlgorithmDescription.html> [Citado 1-1-2014].

Iriarte, E.; A. Foyo, M. A. SÁnchez \& C. Tomillo, 2009. The origin and geochemical characterization of red ochres from the Tito Bustillo and Monte Castillo caves (Northern Spain). Archaeometry 51 (2): 231-251.

IRIBARREN, J., 1956 Investigaciones arqueológicas de Guanaqueros. Boletín del Museo Arqueológico de La Serena 8: 10-22.

IRIBARREN, J., 1958. Nuevos hallazgos arqueológicos en el cementerio indígena de La Turquía-Hurtado. Arqueología Chilena 4: 13-40.

Iribarren, J., 1970. Arqueología y antecedentes históricos del valle del río Hurtado. La Serena: Ediciones del Museo Arqueológico de La Serena.

Iribarren, J., 1973a. Pictografías en las provincias de Atacama y Coquimbo, Chile. Boletín del Museo Arqueológico de La Serena 15: 115-132.

IRIBARREN, J., 1973b. Geoglifos, pictografías y petroglifos de Chile. Boletín del Museo Arqueológico de La Serena 15: 133-159.

Keyser, J., 2007. Direct evidence for the use of indirect percussion in petroglyph manufacture. International Newsletter on Rock Art 49: 25-27.

Krishna, R. \& G. KumaR, 2010-2011. Understanding the creation of small conical cupules in Daraki-Chattan, India. Prehistoire, art et societies 65-66: 216-217.

Kuzmanic, I. \& G. Castillo, 1986. Estadio Arcaico en la costa del norte semiárido de Chile. Chungara 16-17: 89-94.

Lahlil, S.; M. Lebon, L. Beck, H. Rousselière, C. Vignaud, I. Reiche, M. Menu, P. Paillet \& F. Plassard, 2012. The first situ micro-Raman spectroscopic analysis of prehistoric cave art of Rouffignac St-Cernin, France. Journal of Raman Spectroscopy 43: 1637-1643 
Llagostera, A.; R. Weisner, G. Castillo, M. Cervellino, M. A. Costa, L. Ortlieb \& J. VÁsquez, 1998. Estudio del Complejo Arqueológico Huentelauquén bajo una perspectiva macroespacial y multidisciplinaria. Informe Final proyecto Fondecyt 1960036.

Martens, W.; R. Frost \& J. T. Kloprogge, 2003. Raman spectroscopic study of the basic copper sulphates-implications for copper corrosion and 'bronze disease.' Journal of Raman Spectroscopy 34: 145-151.

McDonald, J.; K. Steelman, P. Veth, J. Mackey, J. Loewen, C. R. THURBER \& T. P. GUILDERson, 2014. Results from the first intensive dating program for pigment art in the australian arid zone: insights into recent social complexity. Journal of Archaeological Science 46: 195-204.

MenA, F., 1983. Excavaciones arqueológicas en Cueva Las Guanacas (RI-16). XI región de Aysén. Anales del Instituto de la Patagonia 14: 65-75.

Méndez, C., 2008. Cadenas operativas en la manufactura de arte rupestre: un estudio de caso en El Mauro, valle cordillerano del norte semiárido de Chile. Intersecciones en Antropología 9: 145-155.

Méndez, C.; A. Troncoso, D. Pavlovic \& D. Jackson, 2009. Movilidad y uso del espacio entre cazadores recolectores tardíos en espacios cordilleranos del norte semiárido de Chile. Intersecciones en Antropología 10: 313-326.

Mostny, G. \& H. Niemeyer, 1983. Arte rupestre chileno. Santiago: Ministerio de Educación.

Moya, F., 2015. Variabilidad tecnológica en las pinturas rupestres de la cuenca hidrográfica del río Limarí. Memoria para optar al título de Arqueóloga. Departamento de Antropología, Universidad de Chile, Santiago.

Moya, F.; F. Armstrong, M. Basile, G. Nash, A. Troncoso \& F. Vergara, 2014. On site and post site analysis of pictographs within the San Pedro Viejo de Pichasca rock shelter, Limarí valley, North Central Chile. Proceedings of the University of Bristol Spelaeological Society 26 (2): 171-184.

Niemeyer, H. \& V. León, 2001. Arte rupestre precolombino en el Tinguiririca. Provincia de Cochalgua. Sexta Región de Chile. Santiago: Gráfica Escorpión.

Niemeyer, H. \& D. Ballereau, 2004. Arte rupestre del río Grande, cuenca del río Limarí, norte chico, Chile. Chungara 36 (1):37-101.

Niemeyer, H. \& G. Castillo, 1996. Los yacimientos arqueológicos del estero San Pedro de Quiles. Boletín del Museo Arqueológico de La Serena 19: 53-72.

PAvlovic, D., 2004. Dejando atrás la tierra de nadie: asentamientos, contextos y movilidad de las comunidades alfareras tempranas del Choapa. Werken 5: 39-46.

Prisloo, L., 2007. Rock hyraces: a cause of San rock art deterioration? Journal of Raman Spectroscopy 38: 496-503.

Quevedo, S., 1998. Punta Teatinos: biología de una población arcaica del norte semiárido chileno. Tesis para optar al grado de Doctor, Facultad de Filosofía y Letras, Universidad de Buenos Aires, Buenos Aires.

RapP, G., 2009. Archaeomineralogy. Berlin: Springer.

San Francisco, A. \& B. Ballester, 2010. La economía y las representaciones: ensayo sobre la producción minero-metalúrgica durante el período medio en la región de Atacama. Il Quattrocento 4: 139-159.

SChiappacasse, V. \& H. Niemeyer, 1964. Excavaciones de un conchal en el pueblo de Guanaqueros (Provincia de Coquimbo). En Actas del III Congreso Chileno de Arqueología, pp. 235-262. Viña del Mar: Sociedad Chilena de Arqueología.
Seguel, R.; G. Cantarutti, F. Eisner, G. Román, R. Acevedo \& A. VILLAGRÁN, 2005. Alteración del pigmento negro en la alfarería Diaguita: ¿negro intenso/negro alterado? Fondo de Apoyo a la Investigación Patrimonial Informes 2015: 121-137. Santiago.

SepúlvedA, M., 2009. Aspectos tecnológicos en la pintura rupestre. Reflexiones elaboradas a partir de análisis fisicoquímicos aplicados al estudio de las pinturas de la localidad del río salado (norte de Chile). En Crónicas sobre la piedra. Arte Rupestre en las Américas. M. Sepúlveda, M., Briones, L. \& Chacama, J., Eds., pp. 119-128. Santiago: Universidad de Tarapacá.

Sepúlveda, M., 2011. Pinturas rupestres y tecnología del color en el extremo sur de Chile. Magallania 39 (1): 193-201.

Sepúlveda, M.; B. Arriaza, V. Standen, H. Rousseliere, E. van Elslande, C. Santoro \& P. Walter, 2015a. Análisis microestratigrafícos de recubrimientos corporales de una momia Chinchorro, extremo norte de Chile. Chungara 47 (2): 239-248.

SePúlvedA, M.; V. Figueroa \& J. CÁrCAmo, 2014. Pigmentos y pinturas de mineral de cobre en la Región de Tarapacá, norte de Chile: Nuevos datos para una tecnología pigmentaria prehispánica. Estudios Atacameños 48: 23-37.

Sepúlveda, M.; V. Figueroa \& S. Pages-Camagna, 2013a. Copper pigment making in the Atacama desert (northern Chile). Latin American Antiquity 24 (4): 467-482.

SepúlvedA, M. \& E. Laval, 2010. Aplicación y aplicabilidad de métodos físico-químicos para el estudio de las pinturas rupestres. Ejemplo de estudio en la localidad de río Salado (norte de Chile). En Actas de XVII Congreso Nacional de Arqueología Chilena, tomo ii: 825-834. Valdivia: Universidad Austral-Sociedad Chilena de Arqueología.

Sepúlveda, M.; E. Laval, L. Cornejo \& J. ACAPari, 2012. Elemental characterisation of pre-hispanic rock art and arsenic in northern Chile. Rock Art Research 29 (1): 93-107.

Sepúlveda, M.; D. Valenzuela, L. Cornejo, H. Lienqueo \& H. RousSELIÈRE, 2013b. Óxidos de manganeso en el extremo norte de Chile: abastecimiento, producción y movilidad del color negro durante el Período Arcaico. Chungara 45 (1): 143-159.

Steelman, K. \& M. Rowe, 2012. Radiocarbon dating of rock paintings: Incorporating pictographs into the archaeological record. En $A$ companion to rock art, J. McDonald \& P. Veth, Eds. pp. 565-582. Oxford: Blackwell.

Steelman, K.; R. Rickman, M. Rowe, T. Boutton, J. Russ \& N. Guidon, 2002. Accelerator mass spectrometry radiocarbon ages of an oxalate accretion and rock paintings at Toca do Serrote da Bastiana, Brazil. acs Symposium Series 831: 22-35.

Tomasini, E.; M. Basile, N. Ratto \& M. Maier, 2012a. Evidencias químicas de deterioro ambiental en manifestaciones rupestres: un caso de estudio del oeste tinogasteño (Catamarca, Argentina). Boletín del Museo Chileno de Arte Precolombino 17 (2): 27-38.

Tomasini, E.; E. Halac, M. Reinoso, E. Liscia \& M. Maier, 2012b. Micro-Raman spectroscopy of carbon-based black pigments. Journal of Archaeological Science 43: 1671-1675.

Troncoso, A., 2005. Hacia una semiótica del arte rupestre de la cuenca superior del río Aconcagua, Chile central. Chungara 37 (1): 21-35.

Troncoso, A. \& Armstrong, F. En Prensa. Ontología, historia y la experiencia del arte rupestre en el centro norte de Chile. En Sentidos indisciplinados, J. R. Pellini, A. Zarankin \& M. Salerno, Eds. Madrid: JAs Arqueología.

Troncoso, A.; F. Armstrong, F. Vergara, P. Urzúa \& P. Larach, 2008. Arte rupestre en el valle El Encanto (Ovalle, Región de Coquimbo): hacia una revaluación del sitio-tipo del estilo Limarí. Boletín del Museo Chileno de Arte Precolombino 13 (2): 9-36. 
Troncoso, A.; F. Moya, M. Sepúlveda \& J. Cárcamo, 2015. First absolute dating of andean hunter gatherer rock art paintings from north central Chile. Archaeological and Anthropological Science. doi 10.1007/s12520-015-0282-z

Troncoso, A. \& Pavlovic, D., 2013. Historias, saberes y prácticas: un ensayo sobre el desarrollo de las comunidades alfareras del norte semiárido de Chile. Revista Chilena de Antropología 27: 101-140.

Troncoso, A.; F. Vergara, D. Pavlovic, P. González, M. Pino, P. Larach, A. Escudero, N. Lamura, F. Moya, I. Pérez, R. Gutiérrez, D. Pascual, C. Belmar, M. Basile, P. López, C. Dávila, M. VÁsqueZ \& P. Urzúa, 2016. Dinámica espacial y temporal de las ocupaciones prehispánicas en la cuenca hidrográfica del río Limarí (30 Lat. S). Chungara 48 (2): 199-224.

Vergara, F. \& A. Troncoso, 2015. Rock art, technique and technology: An exploratory study of hunter gatherer and agrarian communities in prehispanic Chile (500 to $1450 \mathrm{CE}$ ). Rock Art Research 32 (1): 31-45.

UrLiksen, C., 1990. Mapa metalogénico de Chile entre los $18^{\circ}$ y $34^{\circ} \mathrm{S}$. Santiago: Servicio Nacional de Geología y Minería.
Valenzuela, D., 2007. Arte, tecnología y estilo: propuesta teórico metodológica para el estudio de la producción en grabados rupestres. Tesis para optar al grado de Magíster, Departamento de Antropología, Universidad de Tarapacá, Arica.

Valenzuela, D., 2012. Decisiones tecnológicas, conocimiento tecnológico y paisaje en los grabados rupestres del valle de Lluta, valles occidentales, norte de Chile. En Actas del XVIII Congreso Nacional de Arqueología Chilena, pp. 207-216. Santiago: Sociedad Chilena de Arqueología-Universidad de Chile.

Vergara, F., 2013. El lado material de la estética en el arte rupestre. Boletín del Museo Chileno de Arte Precolombino 18 (2): 33-47.

Vandenabeele, P., B. Wehling, L. Moens, H. Edwards, M. de Reu \& G. VAN HOOYDONK, 2000. Analysis with micro-Raman spectroscopy of natural organic binding media and varnishes used in art. Analytica Chimica Acta 407: 261-274.

Watchman, A., S. O'Connor \& R. Jones, 2005. Dating oxalate minerals 20-45 ka. Journal of Archaeological Science 32: 369-374.

WhitTACKer, J., S. Koeman \& R. TAYlor, 2000. Some experiments in petroglyphs technology. International Rock Art Congress (IRAC) Proceedings 1: 155-168. 